\title{
AS MUTAÇÕES CONSTITUCIONAIS E A (IN) EFETIVIDADE DOS DIREITOS FUNDAMENTAIS: ENTRE LEGITIMIDADE E ATIVISMO JUDICIAL
}

\author{
Patrícia Spagnolo Parise Costa ${ }^{1}$ \\ Rejaine Silva Guimarães ${ }^{2}$
}

\section{Resumo}

Buscando a efetividade das normas constitucionais, especialmente, daquelas definidoras de direitos fundamentais, a prática interpretativa do Supremo Tribunal Federal tem levado às mutações constitucionais, com fundamento na teoria discursiva de Robert Alexy. Contudo, tal atuação tem sido rebatida, sob o argumento de ativismo, com fulcro nas ideias de Ronald Dworkin. Objetivou-se analisar as teorias dos referidos filósofos pontuando caminhos para uma interpretação condizente com preceitos do Estado Democrático de Direito. Concluiu-se que os poderes políticos, notadamente, o Legislativo, precisam ser mais atuantes diante das novas demandas de uma sociedade plural, evitando, assim, a expansão desmedida no âmbito da jurisdição constitucional.

Palavras-chave: Direitos. Supremo Tribunal Federal. Efetividade. Ativismo. Mutações constitucionais.

\section{THE CONSTITUTIONAL MUTATIONS AND THE (IN) EFFECTIVENESS OF FUNDAMENTAL RIGHTS: BETWEEN LEGITIMACY AND JUDICIAL ACTIVISM}

\begin{abstract}
Intending to provide effectiveness of constitutional rules, especially those on fundamental rights, the interpretative practice of the Supreme Court has led to constitutional mutations, based on the discursive theory of Robert Alexy. However, such action has been refuted, under the argument of activism, according to the ideas of Ronald Dworkin. The study aimed to analyze the theories of these philosophers directed to an interpretation consistent with precepts of the Democratic State of Law. The political powers, especially the Legislative, need to be more active to face the new demands of a plural society, avoiding excessive expansion of constitutional jurisdiction.
\end{abstract}

Keywords: Rights. Federal Supreme Court. Effectiveness. Activism. Constitutional changes.

\section{INTRODUÇÃO}

O procedimento de reforma das normas da Constituição brasileira já não ocorre somente por meio de emendas constitucionais, mas também por meio da chamada via informal ou difusa, ou mutação constitucional.

A mutação constitucional decorre da interpretação do Supremo Tribunal Federal, dos usos e costumes, da construção judicial. Altera o conteúdo da norma, sua significação e

\footnotetext{
${ }^{1}$ Mestra em Direito, advogada, professora de Direito Constitucional da Universidade de Rio Verde.

${ }^{2}$ Doutora em Ciências Sociais, Mestra em Direito, advogada, professora da Universidade de Rio Verde.
} 
alcance, sem qualquer modificação no texto constitucional. Busca, em tese, compatibilizar a Constituição com o dinamismo dos fatos sociais, ou seja, trazer efetividade às normas constitucionais, especialmente, no que tange aos direitos fundamentais.

O tema mostrou-se relevante porque a efetividade normativa da Constituição brasileira é um dos temas mais persistentes na atualidade. Tomando-se como pressuposto o fato de que uma Constituição não pode ficar engessada diante da dinâmica social e mais, que não pode ficar aquém dos fatores reais de poder que norteiam a sociedade, buscam-se maneiras de manter o corpo constitucional atualizado, em uma realidade legislativa que nem sempre traz essa possibilidade. Tanto mais porque o modelo adotado pela Constituição brasileira se caracteriza pela presença de normas programáticas, o que relativiza a efetividade jurídica e social das normas constitucionais. Neste cenário, a prática interpretativa do Supremo Tribunal Federal tem se mostrado pautada na discricionariedade e na ponderação de valores, esta norteada pelo princípio da proporcionalidade, o que acaba levando a acirradas discussões no âmbito da ciência jurídica, já que não há um consenso sobre a legitimidade da corte constitucional brasileira em termos de interpretação de diversos casos que envolvam direitos fundamentais. Ademais, as decisões em âmbito de jurisdição constitucional têm um impacto em toda a sociedade e no próprio direito brasileiro.

Desta forma, emergiram os seguintes questionamentos: a mutação constitucional seria um instrumento legítimo de modificação constitucional e apropriado para reafirmar a força normativa da Constituição brasileira, na busca de concretização de suas normas, em especial, daquelas definidoras de direitos fundamentais? Este tipo de reforma, decorrente do chamado Poder Constituinte Difuso, configuraria prática ativista? Existiriam limites para a interpretação das normas constitucionais, em especial, no que tange às mutações constitucionais?

Objetivou-se, portanto, analisar criticamente o fenômeno da mutação constitucional, sua legitimidade no âmbito da interpretação feita em sede de jurisdição constitucional e se sua prática seria legítima ou denotaria ativismo judicial, a partir do paralelo traçado entre as teorias de Ronald Dworkin e Robert Alexy.

Os estudos foram baseados em pesquisa exploratória, envolvendo levantamento bibliográfico, com a utilização de obras de renomados autores, além de artigos de revistas científicas e casos julgados pelo Supremo Tribunal Federal, com vistas à reflexão e análise dos diversos aspectos inerentes ao tema. 


\title{
2 DA EFETIVIDADE DAS NORMAS CONSTITUCIONAIS
}

A efetividade das normas constitucionais tem sido tema de persistente estudo pelos juristas, dada sua fundamental importância no que se refere à concretização dos preceitos constitucionais.

Para que se tenha a exata ideia da amplitude do tema, preliminarmente, há de se entender que nem sempre às normas constitucionais foi atribuído o patamar de normas jurídicas. Barroso (2009, p. 218) explica:

[...] uma das grandes mudanças de paradigma ocorridas ao longo do século XX foi a atribuição à norma constitucional do status de norma jurídica. Superou-se, assim, o modelo que vigorou na Europa até meados do século passado, no qual a Constituição era vista como um documento essencialmente político, um convite à atuação dos Poderes Públicos. [...] Uma vez investida na condição de norma jurídica, a norma constitucional passou a desfrutar dos atributos essenciais do gênero, dentre os quais a imperatividade.

Na condição de norma jurídica hierarquicamente superior, há de se entender, também, que a norma constitucional, além de constituir ideário do Estado, é provida de sanção e eficácia jurídica. Portanto, as normas constitucionais devem ser cumpridas de modo a atingir a máxima efetividade possível, fazendo valer a normatividade da Constituição.

Em se tratando da efetividade das normas constitucionais, ainda no entendimento de Barroso (2009, p. 220):

\begin{abstract}
Efetividade, em suma, significa a realização do Direito, o desempenho concreto de sua função social. Ela representa a materialização, no mundo dos fatos, dos preceitos legais e simboliza a aproximação, tão íntima quanto possível, entre o dever-ser normativo e o ser da realidade social. [...] A efetividade da Constituição há de assentar-se sobre alguns pressupostos indispensáveis. É preciso que haja, da parte do Constituinte, senso de realidade, para que não pretenda normatizar o inalcançável, o que seja materialmente impossível em dado momento e lugar. Ademais, deverá ele atuar com boa técnica legislativa, para que seja possível vislumbrar adequadamente as posições em que se investem os indivíduos, assim como os bens jurídicos protegidos e as condutas exigíveis. Em terceiro lugar, impõe-se ao poder público vontade política, a concreta determinação de tronar realidade os comandos constitucionais. E, por fim, é indispensável o consciente exercício de cidadania, mediante a exigência, por via de articulação política e de medidas judiciais, da realização dos valores objetivos e dos direitos subjetivos constitucionais.
\end{abstract}

Pode-se afirmar, portanto, que sendo as normas jurídicas, inclusive as constitucionais, providas de imperatividade e considerando-se as situações em que tenham criado direitos subjetivos, individuais, sociais, políticos ou, ainda, difusos, tornam-se elas exigíveis do particular ou do Poder Público, por meio dos instrumentos processuais de 
garantia existentes no ordenamento jurídico. Ora, o próprio direito de ação é um direito subjetivo constitucional.

Ademais, na história constitucional brasileira, a teoria da efetividade ganhou corpo com a Constituição de 1988, ao promover mudanças de paradigma tanto na teoria, quanto na prática constitucional brasileira. Primeiramente, na esfera jurídica, o constituinte atribuiu normatividade plena à Constituição, que se tornou fonte de direitos e obrigações, com aplicabilidade direta e imediata. Reconheceu ao Direito Constitucional, sob o aspecto dogmático, um objeto próprio e autônomo. Enfim, a partir da esfera institucional, contribuiu para a ascensão do Poder Judiciário, atribuindo-lhe um papel de maior destaque na concretização dos valores e dos direitos constitucionais (BARROSO, 2009).

Apesar das conquistas trazidas pela Constituição Federal de 1988, não se pode olvidar que diversas dificuldades em termos de efetividade das normas da Carta Magna decorrem do modelo de constituição adotado pelo Brasil, por influência da doutrina de J.J. Canotilho - a constituição dirigente ou programa. A constituição programa caracteriza-se por traçar um ideal para o Estado, definir as diretrizes que vão orientar toda a atuação do Poder Público, por meio das chamadas normas de eficácia limitada do tipo programático (BARROSO, 2009).

Para que uma norma programática tenha eficácia jurídica e efetividade, é preciso que o preceito constitucional nela inserido seja devidamente regulamentado. Mas não basta somente isso. Carece de vontade política para a formatação de um projeto social viável para atender às necessidades sociais, bem como o investimento em infraestrutura e recursos humanos. Ou seja, são ações que demandam tempo e seriedade.

Não se pode deixar de mencionar também que, no ensejo de garantir a concretização dos preceitos da Constituição de 1988, foram incluídas duas ações diferentes para o enfrentamento da questão da falta de regulamentação das normas constitucionais, conforme expõe Barroso (2009, p. 223):

A nova Carta concebeu dois remédios jurídicos diversos para enfrentar o problema: (I) o mandado de injunção (art. $5^{\circ}$, LXXI), para a tutela incidental e in concreto de direitos subjetivos constitucionais violados devido à ausência de norma reguladora; e (II) a ação de inconstitucionalidade por omissão (art. 102, §2 ${ }^{\circ}$ ), para o controle por via principal e em tese das omissões normativas. Nenhuma das duas fórmulas teve grande sucesso prático, à vista das vicissitudes da técnica legislativa empregada e das limitações que lhes foram impostas pela jurisprudência do Supremo Tribunal Federal. Tal circunstância, todavia, não impediu que juízes e tribunais, na maioria das situações, dessem máxima efetividade às normas constitucionais, na extensão possível permitida pela densidade normativa de seus textos. 
Em especial, o mandado de injunção veio se fortalecendo à medida em que o Supremo Tribunal Federal foi adotando uma postura mais proativa, em virtude da própria inércia dos poderes políticos, mormente do Poder Legislativo. Tome-se como exemplo, conforme Lenza (2016), as decisões do Supremo em sede dos Mis 670, 708 e 712, em que diferentes sindicatos pleiteavam assegurar o direito de greve para seus filiados, em que os votos declararam a omissão legislativa e determinaram a aplicação, no que fosse cabível, da lei de greve do setor privado.

Ressalte-se que, com a referida decisão, o Supremo regulou provisoriamente a questão, até que o Congresso normatize a matéria - o que ainda hoje não ocorreu. Essa persistente inércia do Legislativo leva à falta de efetividade das normas constitucionais, principalmente, dos direitos fundamentais e, por consequência, acarreta uma judicialização exacerbada das questões sociais e políticas da sociedade brasileira.

\section{DAS MUTAÇÕES CONSTITUCIONAIS}

Além dos aspectos anteriormente abordados, é fato que os instrumentos formais de reforma constitucional nem sempre conseguem acompanhar a velocidade com que a dinâmica social se desenrola. O processo legislativo é lento e trabalhoso em muitas situações que envolvem interesses políticos de uma elite. Assim, paralelamente aos mecanismos de reforma previstos, emerge a prática da mutação constitucional, em consequência do fortalecimento do Poder Judiciário na CF/88, já mencionado nessa discussão.

Bulos (2015) ensina que mutação constitucional, fenômeno por intermédio do qual o poder constituinte difuso se manifesta, ocorre na situação em que os textos constitucionais são alterados, sem revisões ou emendas constitucionais.

As constituições, como organismos vivos que são, acompanham o evoluir das circunstâncias sociais, políticas, econômicas, que, se não alteram o texto na letra e na forma, modificam-no na substância, no significado, no alcance e no sentido de seus dispositivos (BULOS, 2015, p. 120).

A mutação constitucional pode ser conceituada como o fenômeno segundo o qual são operadas modificações no sentido, significado e alcance das normas da Constituição, por meio de um procedimento diferente do formalmente previsto. Não é algo recente, tendo sido identificado já no final do século XIX pelos autores tedescos, passando a ser estudado na Espanha, na Itália, em Portugal e, também, na América Latina, pelo México, Venezuela e Brasil. Entretanto, a primeira vez que o termo foi utilizado na literatura jurídica foi na obra 
Wandlungen der deutschen Reichsverfassunganderung, de Paul Laband, escrita em 1895. Nesse livro foi introduzida a diferenciação entre reforma constitucional Verfassungänderung - e mutação constitucional - Verfassungswandlung (KUBLISCKAS, 2009).

Ainda segundo Kublisckas (2009), as mutações constitucionais possuem as seguintes características: informalidade: as modificações decorrem da interpretação das normas constitucionais, das práticas e costumes constitucionais; pluralidade de agentes: as mutações podem ser realizadas pela atuação dos agentes estatais autorizados, bem como da sociedade civil, por meio da opinião pública, grupos de pressão, construções de juristas; distanciamento no tempo: a mutação pode acontecer por meio de lenta consolidação de um novo entendimento sobre um dispositivo constitucional, mediante a comparação entre a compreensão presente e a pretérita de determinado dispositivo, ou, ainda, de forma mais radical, como naquelas ocasiões em que um tribunal fixa novo entendimento sobre matéria já pacificada; manutenção do texto/modificação da norma: as mutações mudam a norma constitucional sem mudar o texto da Constituição; sujeição a limites: as mutações somente serão legítimas quando introduzidas com o objetivo de desenvolver, atualizar ou complementar as normas constitucionais escritas, não podendo contrariá-las.

Há de se analisar que o caráter de abertura e elasticidade de uma Constituição pode influenciar em uma maior ou menor prática mutacional. Nesse âmbito, devem-se tecer algumas considerações.

Quanto maior for a natureza principiológica da Constituição, maior o número de situações em que ocorrerão as mutações constitucionais. Isso porque as normas que representam princípios podem oferecer várias opções de concretização, todas válidas. Além disso, os interesses constitucionalmente tutelados, estando em uma posição contraditória, levarão o intérprete a buscar a harmonização dos preceitos no caso concreto. Ademais, a existência de normas que admitem ou carecem de regulamentação, conforme já abordado no presente projeto, é mais um fator que favorece a proliferação das mutações constitucionais (KUBLISCKAS, 2009).

Vale ressaltar que a inércia legislativa, de acordo com jurisprudência do STF, é um perigoso fator de peso para o surgimento da reforma informal, porque se o legislador é incumbido pela Constituição de regulamentar determinada norma constitucional e não o faz, acaba transgredindo a própria manifestação do poder constituinte originário (BULOS, 2015). 
Diversos são os exemplos elucidativos do fenômeno. Um deles se deu em 03/12/2008, quando o STF, no julgamento do RE 466.343, decidiu que não mais caberia prisão civil ao depositário infiel. Com o advento da referida decisão, foi editada a SV n. 25/2009 com intuito de atribuir o efeito erga omnes. Outro exemplo refere-se ao julgamento da ADI 4.277 e da ADPF 132, em 05/05/2011. Na sede destas ações, o Supremo Tribunal Federal reconheceu a união estável entre pessoas do mesmo sexo, inclusive como entidade familiar (LENZA, 2016).

Muito se discutiu, à época, sobre a existência de legitimidade para tal atuação e, também, acerca de possível lesão ao princípio democrático e ao da separação dos poderes.

Observe-se, contudo, que em ambos os casos houve mutação constitucional, ou seja, modificação do sentido e alcance da norma, sem reforma formal do texto. E tal fato se deu em virtude de prolongada inércia do Poder Legislativo.

Ademais, verifica-se a influência da opinião pública, dos grupos de pressão na produção das mutações constitucionais. Neste âmbito, vale trazer a lúmen um caso particular e bastante recente de mutação constitucional: a decisão polêmica proferida em 17 de fevereiro de 2016 e confirmada no dia 02 de setembro de 2016, no Habeas Corpus n. 126292, quando o Plenário, mudando sua jurisprudência anterior, liberou a execução da pena de prisão antes do trânsito em julgado, quando decisões de segundo grau confirmam condenações criminais (STF, 2016). A referida decisão contrariou, na literalidade, o preceito constitucional insculpido no inciso LVII do artigo $5^{\circ}$, segundo o qual "ninguém será considerado culpado até o trânsito em julgado de sentença penal condenatória" (BRASIL, 2015, p.15).

Para o procurador de Justiça Rômulo de Andrade Moreira, membro do Ministério Público baiano, os membros do STF usaram a prerrogativa constitucional de intérpretes da Constituição contra o princípio democrático e questionou a referida decisão na Comissão Interamericana de Direitos Humanos, ligada à Organização dos Estados Americanos (OEA) (LUCHETE, 2016).

O ex-ministro Eros Grau (2014) entende que, com esta decisão, o STF, além de contrariar uma cláusula pétrea da Constituição, nega, inclusive, o exercício de direitos políticos a quem tenha sido condenado não ainda na última instância. Para ele, o direito positivo brasileiro tem sido reescrito pelos juízes, que, inclusive, além de exercerem o controle da constitucionalidade e da razoabilidade das leis, acabam cedendo à pressão da opinião pública, quando deveriam se ater aos aspectos jurídicos que envolvem o caso 
concreto. Em suas palavras: "não se bastam em controlar a constitucionalidade das leis e, quando lhes parece que elas não são conformes a razoabilidade, negam-se a aplicá-las!" (GRAU, 2014, p. 38).

Veja-se, portanto, que a mutação constitucional, a princípio, seria um instituto apto para buscar a efetividade das normas constitucionais, em especial daquelas que definem direitos fundamentais. Mas acaba por criar, de fato, uma dicotomia entre a atuação da Corte Maior e a opinião de diferentes filósofos e doutrinadores. Muitos são os críticos que se colocam contrários à produção das mutações constitucionais, uma vez que são produzidas a partir de uma discricionariedade do julgador, ou seja, há um pesado conteúdo político e valorativo influenciando as decisões em âmbito de jurisdição constitucional. Ora, toda a celeuma está inserida no contexto da chamada Nova Hermenêutica Constitucional, que emerge em um cenário de profundas transformações nos ideários de cunho teórico, filosófico e ideológico do Direito, decorrentes do fracasso e insuficiência dos preceitos do positivismo e a consequente ascensão do neopositivismo, conforme se verá no próximo tópico.

\section{INTERPRETAÇÃO CONSTITUCIONAL, MUTAÇÕES CONSTITUCIONAIS E ATIVISMO JUDICIAL}

Esclareça-se, preliminarmente, que as mutações constitucionais decorrem da prática interpretativa do Supremo Tribunal Federal, em especial, quando no caso concreto, se constatam tensões entre direitos fundamentais. Para que se compreenda melhor, cabe uma breve nota sobre os novos paradigmas de interpretação constitucional.

A visão voltada à necessidade de interpretação da constituição, em virtude de se considerá-la como norma suprema, só veio a ser consolidada na segunda metade do século $\mathrm{XX}$, mais precisamente após os anos 50. O direito constitucional, até então, era um direito sem interpretação (PEREZ ROYO, 2014).

Até meados do século XX, os métodos tradicionais de interpretação jurídica buscavam a neutralidade em sua aplicação, afastando valores, inclusive, já que integrados em plena teoria positivista. Acontece que, em se tratando de interpretação das constituições, acabaram tornando-se insuficientes em muitas situações, pois prezavam pela simples subsunção do caso à norma (BARROSO, 2013).

No exercício interpretativo a partir da visão tradicional, portanto, percebe-se que a análise do caso concreto perante a norma converge para a subsunção. Este padrão interpretativo, típico do positivismo jurídico, perdurou até que a dinâmica social mostrou sua 
insuficiência diante dos novos fatos da vida. Houve, então, a necessidade de se pensar em novos paradigmas de hermenêutica capazes de lidar de forma adequada com as questões contemporâneas. Barroso (2013, p. 334) ilustra bem este cenário: “a nova interpretação constitucional surge para atender às demandas de uma sociedade que se tornou bem mais complexa e plural".

No Brasil, os novos paradigmas hermenêuticos superaram os conceitos do pensamento jurídico clássico no final do século $\mathrm{XX}$, com a finalidade de adotar uma postura mais lógica, criativa e justa quando da interpretação constitucional. Neste cenário, Barroso (2013) leciona que emergem três novos paradigmas hermenêuticos: a superação do formalismo jurídico, a nova cultura jurídica pós-positivista e a ascensão do direito público e a centralidade da Constituição. Cabe uma análise sucinta de cada um deles, em razão de sua essencialidade no novo formato de interpretação da Constituição.

A superação do formalismo jurídico ocorreu por meio do abandono da ideia clássica de que o direito era a expressão máxima da razão e da justiça, e que sempre haveria uma norma perfeita no ordenamento jurídico para que o juiz realizasse a subsunção. Com o advento do pensamento neopositivista, houve uma mudança de perspectiva no direito. A ciência, que classicamente era voltada para as relações privadas, passou a valorizar as normas de caráter público, o que resultou em uma visão de centralidade e primazia da Constituição. Atrelado a esta ideia, entendeu-se que qualquer interpretação jurídica deveria ser realizada nos parâmetros dos valores e princípios da Constituição (BARROSO, 2013).

Barroso (2013) aponta outros fatores que influenciaram a adoção de novos elementos de interpretação constitucional, alegando que esta não derrota a interpretação tradicional, mas emerge com vistas a suprir necessidades deficientemente supridas pelo modelo clássico. A nova interpretação surge, assim, para lidar com os casos difíceis, para os quais não existe solução pré-pronta no ordenamento. Existem três situações que levam aos casos difíceis: a) ambiguidade da linguagem, ou seja, termos com múltiplos significados ou indeterminados, que só podem ser definidos junto ao caso concreto, como, por exemplo: servidor público, relevância, urgência, interesse social; b) desacordos morais razoáveis, típicos das sociedades plurais e complexas, nas quais se pensa de maneira diferente sobre temas moralmente controvertidos, como eutanásia, descriminalização das drogas leves; c) conflitos de normas constitucionais ou de direitos fundamentais, o que pode acarretar tensões. 
Vale acrescentar que a importância da interpretação constitucional recai com maior ênfase no âmbito de possíveis tensões entre direitos fundamentais, perante casos concretos nos quais não há uma solução clara na lei. Tanto é assim que, dada a sua essencialidade enquanto instrumentos maiores de limitação ao poder do Estado, Bonavides (2006) acredita no surgimento de uma teoria hermenêutica mais restrita, voltada, especialmente, à interpretação dos direitos fundamentais. É visto que a interpretação destes se reveste de características especiais decorrentes da singularidade de sua problemática. Assim como as normas constitucionais de conteúdo mais amplo, aquelas definidoras de direitos fundamentais requerem vias de interpretação que transcendem os métodos clássicos. Contudo, há de se lembrar que, entre a interpretação constitucional e a dos direitos fundamentais, existe um vínculo estreito, servindo os princípios que regem aquela ao descortinamento do significado das normas definidoras desses direitos.

Ressalta-se que não é possível mais transferir validamente os problemas de uma sociedade para os textos, vez que mudanças constitucionais profundas têm sido verificadas no decorrer da história do constitucionalismo em virtude das alterações na gramática das práticas sociais e, sendo assim, emerge a necessidade da ressignificação dos próprios direitos fundamentais (CARVALHO NETTO, 2012). Neste cenário, Dworkin (2006) acrescenta que o direito humano fundamental é o de ser tratado pelas instituições que detêm a autoridade com uma postura que reflita a devida consideração e respeito pela dignidade de cada um.

Mas, para que se fale em interpretação das possíveis tensões surgidas entre direitos fundamentais nos casos concretos, há de se ter como pressuposto o conhecimento de que, se por um lado, eles promovem a inclusão social, por outro e ao mesmo tempo, levam a exclusões fundamentais. "Este é um desafio à compreensão dos direitos fundamentais; tomálos como algo permanentemente aberto, ver a própria Constituição formal como um processo permanente, e portanto mutável, de afirmação da cidadania" (CARVALHO NETTO, 2012, p. 43).

No ensejo de se encontrar caminhos viáveis para a concretização desses direitos, Bonavides (2006) referencia o publicista alemão Paul Kirchhof, que desenvolveu oito teses especificamente voltadas à interpretação dos direitos fundamentais. A primeira tese refere-se à qualidade dos direitos fundamentais: direitos que se colocam a um só tempo como um reservatório da liberdade e um limite ao arbítrio do Estado e configuram o Estado negativo. A segunda tese é fundada no Estado positivo, cujo dever constitucionalmente atribuído é o de 
tutelar os direitos fundamentais, assumindo concretamente o dever de proteger a liberdade. A terceira remete à importância do princípio da separação de poderes, vislumbrando mais interpretação nos órgãos de soberania que aplicam os direitos (Executivo e Legislativo) do que no Judiciário, uma vez que este só se move quando provocado.

Observe-se que, em relação à terceira tese, Bonavides a considera paradoxal em um particular. É certo, sim, que o Judiciário só age mediante provocação, mas é visto que o papel interpretativo da corte constitucional brasileira tem ganhado amplitude, em decorrência do fortalecimento da jurisdição constitucional na seara do neopositivismo. Ressalte-se a adesão de Bonavides ao ideário de interpretação utilizado pela corte constitucional brasileira, conforme se discutirá adiante.

A quarta tese de Kirchhof, partindo de uma dimensão histórica acerca dos direitos fundamentais, leva à noção de uma prática interpretativa cuja finalidade é a de atualizar a Constituição, tornando-a moldável à dinâmica social. Em reconhecimento à função participativa do cidadão, é delineada a quinta tese, ou seja, ao indivíduo é outorgada uma expectativa legítima de participar das organizações estatais, na administração e nos programas públicos de financiamento. A sexta tese refere-se ao papel arbitral que é desempenhado pelo Estado, tanto pela via legislativa como judicial, nas situações em que existam colisões das liberdades. A sétima pauta-se em uma interpretação dos direitos fundamentais em que a liberdade nunca deverá conceder o direito a alguém de subjugar a liberdade dos demais sujeitos sociais. Por fim, a oitava tese baseia-se no preceito da liberdade como diretriz da interpretação dos direitos fundamentais (BONAVIDES, 2006).

O conjunto de teses descrito por Kirchhof é provido de importante valor norteador no campo teórico. Possivelmente, tais diretrizes serviriam bem para a prática hermenêutica no Brasil, com vistas à efetividade jurídica do texto constitucional. Tanto mais se entrelaçadas com a teoria de Ronald Dworkin, descrita logo mais neste estudo. Mas é importante alertar que a questão da adequada interpretação dos conflitos entre direitos fundamentais vem tomando corpo e fomentando acirradas discussões sobre a maneira como esses novos parâmetros hermenêuticos devem ser praticados, de forma a se evitar leituras abusivas por parte do corte maior brasileira, o que colocaria em risco a concretização dos direitos fundamentais, o princípio democrático, o da separação dos poderes e a essência do próprio direito. 
A atuação do Supremo Tribunal Federal na produção das mutações constitucionais vem sendo pautada nos parâmetros da discricionariedade judicial, com utilização do princípio da proporcionalidade no uso da técnica da ponderação. Esta visão interpretativa coloca o julgador como copartícipe na criação das normas. Tal postura, no intuito de dirimir conflitos não somente entre normas gerais, mas, também, entre aquelas definidoras de direitos fundamentais, gera a dúvida se, de fato, a Corte tem conseguido concretizar tais direitos ou se a prática foi ativista, lesiva aos preceitos do Estado Democrático de Direito.

Na verdade, no Brasil, a prática interpretativa em âmbito da jurisdição constitucional tem demonstrado que o Supremo vem incorporando a teoria da argumentação de Robert Alexy. Os ministros do STF, como Gilmar Mendes e Luís Roberto Barroso, em especial, traçam todo um contexto de nova interpretação constitucional, baseado nas ideias alexyanas.

Para iniciar, Barroso (2013) ratifica as lições de Alexy sobre a superação da separação entre Direito e Moral, alegando que quando a norma não fornece a resposta, é necessário que o direito se aproxime da filosofia moral. Como consequência do neopositivismo, a lei não perde sua importância, mas o direito não cabe mais integralmente na norma jurídica, o valor justiça está além dela.

Corroborando este pensamento, Mendes (2014) enfatiza que é típica das constituições atuais a incorporação de valores morais ao domínio jurídico, não se limitando as Constituições a somente limitar a atuação do Estado e a discriminar competências. Para o autor, "as constituições contemporâneas absorvem noções de conteúdo axiológico e, com isso, trazem para a realidade do aplicador do direito debates políticos e morais" (MENDES, 2014, p. 81).

Barroso (2013) acredita que a nova hermenêutica jurídica incorpora todo um novo modelo, destinado justamente a lidar com casos complexos de uma sociedade cada vez mais dinâmica. Trata-se da normatividade dos princípios, do ajustamento das colisões de normas constitucionais e da ponderação e argumentação jurídica. A norma não possui normatividade suficiente até que seja integrada pelos fatos, o problema torna-se parte da norma e o intérprete torna-se coparticipante do processo de criação do direito relacionado ao caso concreto. Sua pré-compreensão, seus valores ganham importância. A norma é produzida, portanto, a partir do caso concreto.

Ainda nas palavras de Barroso (2013), assume papel de importância na prática interpretativa a ponderação ou sopesamento, que na tradição alemã consiste em um aspecto do 
princípio da proporcionalidade. Para Alexy (2008), a ponderação envolve a busca da solução ótima quando se depara com princípios concorrentes e o princípio da proporcionalidade é a chave para que se possa resolver a ponderação.

Tratando com mais detalhes sobre a ponderação proposta por Alexy, Barroso (2013) explica que é uma técnica interpretativa para dirimir conflito de normas constitucionais, mormente sobre direitos fundamentais. Exerce-se mediante concessões recíprocas, sendo realizada em três etapas: a) identificam-se as normas relevantes aplicadas ao caso; b) identificam-se os fatos relevantes; c) testam-se as soluções possíveis para ver a que melhor se coaduna com o conjunto da Constituição.

A argumentação jurídica é outro elemento integrante dos novos paradigmas da Hermenêutica da Constituição. A regra geral que legitima a função jurisdicional é a separação de poderes: o Legislativo faz as leis; o juiz não cria o direito, mas o aplica de acordo com as regras do representante que criou o direito. $\mathrm{Na}$ hipótese de o juiz ser coparticipante do processo de criação da norma, a legitimação da sua atuação não pode se fundar somente na separação dos poderes, pelo fato de ele estar criando o direito sem o batismo da representação popular. Eis a importância da argumentação jurídica. Mais do que simples motivação da decisão, consiste na demonstração da racionalidade, da justiça e da correção da decisão. $\mathrm{O}$ juiz precisa explicitar o itinerário que percorreu, por qual razão considerou aquela decisão mais adequada, tem que convencer o máximo de pessoas possível de que aquela era a solução justa para o caso concreto (BARROSO, 2013).

Contudo, Lima (2008) pontua que a teoria dos princípios de Alexy é aplicada de forma distorcida no Brasil. O maior problema na atuação da corte constitucional brasileira repousa, justamente, na insuficiência de uma argumentação jurídica objetiva e transparente. Justifica-se, exaustivamente, a existência da colisão entre os direitos envolvidos nos casos submetidos a julgamento, mas negligencia-se a consistente fundamentação na escolha do direito adequado. Para o autor, vigora na prática do Supremo Tribunal Federal a teoria (jogo) da Katchanga ${ }^{3}$. Ou seja, não é suficiente pensar que se aprendeu a jogar a Katchanga. O

\footnotetext{
3 Para melhor compreensão, segue a anedota da "teoria da Katchanga".

Um rico senhor chega a um cassino e senta-se sozinho em uma mesa no canto do salão principal. O dono do cassino, percebendo que aquela seria uma ótima oportunidade de tirar um pouco do dinheiro do homem rico, perguntou se ele não desejaria jogar.

- Temos roleta, blackjack, texas holden' e o que mais lhe interessar, disse o dono do Cassino.

- Nada disso me interessa, respondeu o cliente. Só jogo a Katchanga.

O dono do cassino perguntou para todos os crupiês lá presentes se algum deles conhecia a tal da Katchanga. Nada. Ninguém sabia que diabo de jogo era aquele.
} 
jogo é mais complexo do que se supõe, uma vez que a própria Katchanga Real representa um problema a ser decifrado. E aponta um exemplo ilustrativo deste pensamento, que foi o caso da pesagem dos botijões de gás, tratado pela ADI 855-2/DF, em que o Estado do Paraná havia criado uma lei que obrigava os revendedores de gás a pesarem os botijões na presença do consumidor. Tal lei seguiu os devidos preceitos do processo legislativo. Mas, o Supremo Tribunal Federal considerou a norma inconstitucional, irrazoável e não proporcional, sem, no entanto, explicar na decisão quais os aspectos da razoabilidade e da proporcionalidade foram violados.

Mas, as críticas em relação às ideias de Alexy vão além do aspecto da distorção do elemento fundamentação jurídica. Dworkin (2010) entende que se vive hoje em uma comunidade de princípios, cujos membros se reconhecem reciprocamente como livres e iguais, com respeito pelas diferenças. Isso significa que os direitos fundamentais - a igualdade e a liberdade reciprocamente reconhecidas a todos em uma comunidade - são compreendidos como princípios opostos e complementares entre si, capazes, por consequência, de gerar tensões. Todas as normas, até mesmo as regras, nada mais são do que densificações desses princípios. Nesse cenário, surge sua teoria interpretativa da única resposta correta: em havendo mais de uma possiblidade juridicamente defensável, decorrente de tensões, o direito sempre tem uma resposta. Durante a interpretação, deve-se buscar uma aplicação racional da norma, a partir da análise da situação individual específica, irrepetível e única sob o ponto de vista de todos os envolvidos, com vistas à garantia da integridade do direito, ou seja, a

Então, o dono do cassino teve uma idéia. Disse para os melhores crupiês jogarem a tal da Katchanga com o cliente mesmo sem conhecer as regras para tentar entender o jogo e assim que eles dominassem as técnicas básicas, tentariam extrair o máximo de dinheiro possível daquele "pote do ouro".

E assim foi feito.

Na primeira mão, o cliente deu as cartas e, do nada, gritou: "Katchanga!" E levou todo o dinheiro que estava na mesa.

Na segunda mão, a mesma coisa. Katchanga! E novamente o cliente limpou a mesa.

Assim foi durante a noite toda. Sempre o rico senhor dava o seu grito de Katchanga e ficava com o dinheiro dos incrédulos e confusos crupiês.

De repente, um dos crupiês teve uma idéia. Seria mais rápido do que o homem rico. Assim que as cartas foram distribuídas, o crupiê rapidamente gritou com ar de superioridade: "Katchanga!"

Já ia pegar o dinheiro da mesa quando o homem rico, com uma voz mansa mas segura, disse: "Espere aí. Eu tenho uma Katchanga Real!". E mais uma vez levou todo o dinheiro da mesa...

Observa-se a partir da anedota que não é suficiente pensar que se aprendeu a jogar a Katchanga. O jogo é mais complexo do que se supõe, uma vez que a própria Katchanga Real representa um problema a ser decifrado. Eis a atuação da corte constitucional brasileira. Desconhece-se as regras (LIMA, 2008). 
segurança de uma decisão fundada em uma norma previamente aprovada e na justiça no caso concreto.

A partir deste entendimento, pode-se dizer que o direito, enquanto um sistema de regras e princípios, não se abre a um juízo discricionário, já que tem sempre uma história institucional a ser reconstruída e que indica a melhor decisão a ser tomada.

Streck (2013) pondera que a discricionariedade hartiana ${ }^{4}$ tem sido reelaborada pelas teorias argumentativas como orientadora de possíveis soluções de conflitos nos hard cases (casos difíceis, nos quais não há uma solução clara na norma). Alexy aceita plenamente a visão de Herbert Hart acerca da textura aberta do direito, porta de entrada para elementos morais ou questões de justiça no âmbito do direito.

Nessa perspectiva, Alexy entende que os casos difíceis não podem ser resolvidos por elementos exclusivos do direito, e neste caso a moral deve prevalecer na tomada de decisão. Este aspecto, entretanto, é rechaçado por Dworkin, no sentido de que, para ele, o conteúdo moral do Direito não o transforma em Moral. O direito continua a operar como tal, de forma que sua aplicação possa se dar dentro de um patamar de segurança jurídica, sem dar abertura a pretensões abusivas (DWORKIN, 2010).

Neste mesmo sentido, pontua-se que o direito é um conceito de interpretação emanado pelas instituições jurídicas e que "as questões a ele relativas encontram, necessariamente, respostas nas leis, nos princípios constitucionais, nos regulamentos e nos precedentes que tenham DNA constitucional, e não na vontade individual do aplicador" (STRECK, 2013, p. 264).

Streck, em explicação da visão dworkiniana, rechaça a postura adotada pela corte constitucional brasileira, fundada na discricionariedade e na ponderação de valores alexyana, pontuando para uma interpretação que venha a convergir no direito como integridade, buscando trazer elementos capazes de condicionar o processo decisório, na defesa de argumentos de princípios que sejam aplicados de maneira coerente, segundo prática jurídica, ou seja, uma aplicação condizente com a racionalidade jurídica. "Ora, se, ao fim e ao cabo, cabe ao intérprete hierarquizar (e escolher) o princípio aplicável, a pergunta inexorável é: qual

\footnotetext{
4 “A herança kelsiana do decisionismo não foi superada até hoje, e a discricionariedade hartiana tem sido, de algum modo, reapropriada pelas teorias argumentativas, só que sob o manto de uma racionalidade argumentativa com a pretensão de dar solução ao problema de uma pós-metódica" (STRECK, 2013, p. 347). Importa lembrar, neste contexto, que Kelsen entedia que nos casos em que a norma não previa com clareza a solução, poderia o juiz valer-se do seu convencimento/discricionariedade para resolver a questão. Este posicionamento leva à reflexão acerca da existência de critérios concretos para avaliação da legitimidade dessas decisões.
} 
a diferença entre o intérprete ponderador e o interprete do positivismo, que discricionariamente escolhe qual a melhor interpretação?” (STRECK, 2013, p. 354). Isso significa, portanto, que a prática de interpretação brasileira, baseada na teoria da argumentação jurídica de Alexy, nada mais representa do que um retorno ao decisionismo kelsiano.

Percebe-se que a jurisdição constitucional brasileira tem se investido de uma forma bastante proativa, acarretando tensões, em especial, com o Poder Legislativo, ferindo, inclusive, o princípio democrático. Veja-se, se o juiz se torna coparticipante do processo de criação da norma, precipuamente no controle de constitucionalidade das leis - sua atribuição principal conferida pela Constituição no caput do artigo 102 da Constituição Federal (BRASIL, 2015), este agir pode ser confundido com invasão de poder, ou seja, com o chamado ativismo judicial, o que torna este novo paradigma de interpretação questionável quanto aos seus limites.

Ora, na medida em que a discricionariedade é regra nas decisões do STF, difícil imaginar como isso não levaria à arbitrariedade. Há de se propor uma interpretação pautada nos ensinamentos de Dworkin, no sentido de uma racionalidade jurídica, ou seja, de se proferir decisões que reconheçam os direitos efetivamente, não criá-los com base em argumentos de natureza subjetiva ou política, impondo-se como limites os princípios da democracia e da separação dos poderes. Tal pensamento entrelaça-se com o ideal procedimentalista de Habermas, no sentido de orientar a ação do juiz no sentido de se resguardar a segurança jurídica das decisões.

Possivelmente, o fortalecimento da atuação legislativa no cenário de uma sociedade plural, em que se requer uma constante reflexão sobre o direito como instrumento de atendimento às demandas sociais, com vistas ao fortalecimento e concretização dos direitos fundamentais, seria uma possível saída para a questão. É fulcral que o Poder Legislativo tenha consciência do seu papel de órgão fixador das normas jurídicas, e mais, não pode mais a atuação legislativa colocar-se em uma postura inerte e desatenta às expectativas sociais, constantemente redesenhadas em virtude da complexidade da vida. A inércia do Poder Legislativo e, também, do Executivo tem sido fator determinante para uma crescente judicialização das relações políticas e sociais no Brasil, o que, fatalmente, leva às mutações constitucionais, mais similares, em muitos casos, à prática ativista do que a uma prática 
interpretativa voltada à real concretização dos direitos fundamentais e aos preceitos do Estado Democrático de Direito.

Mesmo porque não existem limites exatos às mutações constitucionais. Bulos (2015, p. 122) pontua, neste sentido:

O único limite que poderia existir, mas de natureza subjetiva e, até mesmo, psicológica, seria a consciência do intérprete em não extrapolar a forma plasmada na letra dos preceptivos supremos do Estado, mediante interpretações deformadoras dos princípios fundamentais que embasam o Documento Maior.

Por fim, sem pretensões de esgotar tema, mesmo porque, por mais que a filosofia reflita e aponte saídas para a atuação da jurisdição constitucional, a realidade brasileira demonstra resistência a tais ponderações, finaliza-se o presente artigo com as palavras do exministro do STF, Eros Grau, acerca do tema: "Eis porque tenho medo dos juízes dos dias de hoje. Dos que decidem como Pilatos e dos neo e pós-positivisas, irrepreensivelmente ativistas judiciais, hermeneutas encantados consigo mesmos, portadores de certezas para mim inalcançáveis" (GRAU, 2014, p. 38).

\section{CONCLUSÃO}

As mutações constitucionais, decorrentes do Poder Constituinte Difuso, são alterações do sentido e do alcance das normas constitucionais, sem que haja reforma formal do texto. Decorrem do exercício de interpretação realizado em âmbito da jurisdição constitucional, a partir dos parâmetros da chamada Nova Hermenêutica, ou seja, por inspiração neopositivista. Em tese, têm por finalidade preencher os vazios da Constituição, frente aos novos fatos sociais, de forma a promover a máxima efetividade das normas constitucionais. Aliás, a questão da efetividade das normas constitucionais é tema recorrente no Brasil. Como a CF/88 é uma Constituição-programa ou dirigente, na medida em que os mecanismos de reforma formalmente previstos não são céleres o suficiente para acompanhar os novos fatos sociais e que a inércia dos poderes políticos, mormente do Poder Legislativo, levam à uma exacerbada judicialização, emerge a mutação constitucional, discutível sob o prisma da soberania popular.

A atual visão interpretativa da Constituição utilizada pela corte constitucional brasileira, baseada nas ideias de Alexy, à "moda brasileira", tem levado à incerteza quanto à efetivação dos direitos fundamentais. Sua atuação, pautada na discricionariedade judicial e na 
proporcionalidade para orientar a ponderação, tem levado a uma postura ativista, lesiva à democracia e à separação dos poderes.

Contrariando esta postura, coloca-se a teoria dworkiniana, segundo a qual se deve buscar uma aplicação racional da norma, a partir da análise da situação individual específica, irrepetível e única sob o ponto de vista de todos os envolvidos, com vistas à garantia da integridade do direito, ou seja, a segurança de uma decisão fundada em uma norma previamente aprovada e na justiça no caso concreto. Contudo, as ideias de Dworkin são impraticáveis na realidade brasileira, uma vez que não há como controlar a atividade judicial sem que isto configure invasão de poder, no sentido de coibir uma técnica interpretativa distante da discricionariedade, mesmo porque, tal ideia, atrelada à ponderação de valores, já está enraizada no pensamento e nas ações de âmbito da jurisdição constitucional.

Mais do que teorias filosóficas, é preciso que os ministros do Supremo Tribunal Federal reflitam sobre sua prática, de forma a não se deixar influenciar por aspectos políticos e subjetivos. Além disso, cabe aos poderes políticos e, essencialmente, ao Legislativo assumir uma postura mais sensível e dinâmica no sentido de regular as novas demandas de uma sociedade cada vez mais complexa e plural, evitando, assim, uma judicialização desmedida das relações políticas e sociais.

\section{REFERÊNCIAS}

ALEXY, Robert. Teoria dos direitos fundamentais. Tradução: Virgílio Afonso da Silva. São Paulo: Malheiros, 2008..

BARROSO, Luís Roberto.. O direito constitucional e a efetividade de suas normas: limites e possibilidades da constituição brasileira. São Paulo: Renovar, 2009.

Curso de direito constitucional contemporâneo. São Paulo: Saraiva, 2013.

BRASIL. Constituição (1988). Constituição da República Federativa do Brasil: promulgada em 5 de outubro de 1988. Organização do texto: Alexandre de Moraes. São Paulo: Atlas, 2015.

BONAVIDES, Paulo. Curso de direito constitucional. 18. ed. São Paulo: Malheiros, 2006.

BULOS, Uadi Lammêgo. Direito constitucional ao alcance de todos. 6. ed. São Paulo: Saraiva, 2015.

CARVALHO NETTO, Menelick., SCOTTI, Guilherme. Os direitos fundamentais e a (in)certeza do direito: a produtividade das tensões principiológicas e a superação do sistema de regras. Belo Horizonte: Fórum, 2012. 
DWORKIN, Ronald. Levando os direitos a sério. 3. ed. Tradução: Nelson Boeira. São Paulo: Editora WMF Martins Fontes, 2010.

GRAU, Eros Roberto. Redistribuir pelo direito? Qual direito? Confluências. Revista Interdisciplinar de Sociologia e Direito. Vol. 16, n. 2, 2014, p. 33-39.

KUBLISCKAS, Wellington Márcio. Emendas e mutações constitucionais: análise dos mecanismos de alteração formal e informal da Constituição Federal de 1988. São Paulo: Atlas, 2009.

LENZA, Pedro. Direito constitucional esquematizado. 20. ed. São Paulo: Saraiva, 2016.

LIMA, George Marmelstein. Alexy à Brasileira ou a Teoria da Katchanga. Disponível em:https://direitosfundamentais.net/2008/09/18/alexy-a-brasileira-ou-a-teoria-da-katchanga/. Acessado em 29/04/2017.

LUCHETE, Felipe. Membro do MP vai a comissão da OEA contra prisão antes de trânsito em julgado. Revista Consultor Jurídico, 26 de fevereiro de 2016. Boletim de notícias.

Disponível em: <http://www.conjur.com.br/2016-fev-26/membro-mp-corte-oea-prisao-antescoisa-julgada>. Acessado em: 28/02/2016.

MENDES, Gilmar., BRANCO, Paulo. Curso de direito constitucional. 9. ed. rev. e atual. São Paulo: Saraiva, 2014.

PEREZ ROYO, Javier. Curso de derecho constitucional. Decimocuarta ediciòn. Madrid: Marcial Pons, 2014.

SUPREMO TRIBUNAL FEDERAL. Acompanhamento Processual. Disponível em: $<$ http://www.stf.jus.br/portal/processo/verProcessoAndamento.asp?numero=126292\&classe $=$ HC\&origem $=A P \&$ recurso=0\&tipoJulgamento=M>. Acessado em 02/09/2016.

STRECK, Lenio Luiz. Porque a discricionariedade é um grave problema para Dworkin e não o é para Alexy. Revista Direito e Práxis - UERJ. Vol. 4, n. 7, 2013. p. 343-367. 